\title{
Brief communication: Glacier thickness reconstruction on Mt. Kilimanjaro
}

\author{
Catrin Stadelmann, Johannes Jakob Fürst, Thomas Mölg, and Matthias Braun \\ Institute of Geography, Friedrich-Alexander University Erlangen-Nürnberg, 91058 Erlangen, Germany
}

Correspondence: Catrin Stadelmann (catrin.stadelmann@fau.de)

Received: 17 December 2019 - Discussion started: 3 February 2020

Revised: 12 August 2020 - Accepted: 17 August 2020 - Published: 15 October 2020

\begin{abstract}
Glaciers on Kilimanjaro are unique indicators for climatic change in the tropical midtroposphere of Africa, but their disappearance seems imminent. A key unknown is their present ice thickness. Here, we present thickness maps for the Northern Ice Field (NIF) and Kersten Glacier (KG) with mean values of 26.6 and $9.3 \mathrm{~m}$, respectively, in 2011. In absence of direct measurements on $\mathrm{KG}$, multitemporal satellite information was exploited to infer past thickness values in areas that have become ice-free and therefore allow glacierspecific calibration. In these areas, $\mathrm{KG}$ is unrealistically thick in the existing consensus estimate of global glacier ice thickness.
\end{abstract}

\section{Introduction}

Tropical glaciers at high elevations are unique climate indicators for the tropical midtroposphere (e.g., Kaser, 2001; Mölg et al., 2009). As one of few tropical locations with still existing glaciers, Mt. Kilimanjaro, a stratovolcano with an elevation of $5895 \mathrm{~m}$ a.s.1., is located in East Africa, close to the Tanzania-Kenya border $\left(3^{\circ} 04^{\prime} \mathrm{S}, 37^{\circ} 21^{\prime} \mathrm{E}\right.$; Fig. 1, overview). In addition to the very high elevation, the freestanding nature of the mountain causes the glacier on top of the summit to be directly exposed to tropospheric flows at higher altitudes, minimizing the forcing of local climate on the glacier and creating a unique opportunity to study the midtroposphere climate.

The modern glacier recession on Kilimanjaro has been well documented, and mapping approaches have shown that from an estimated ice extent of $11.4 \mathrm{~km}^{2}$ in 1912 , only $1.76 \mathrm{~km}^{2}$ remained in 2011, constituting a severe $85 \%$ reduction in glacier area (Cullen et al., 2013). While glaciological research on Kilimanjaro has focused on mapping glacier area and retreat (e.g., Cullen et al., 2013) as well as quantifying the mass and energy balance (Mölg and Hardy, 2004; Mölg et al., 2008, 2009), the research on the ice thickness of different glaciers on Kilimanjaro has been comparably sparse (Bohleber et al., 2017). However, in light of severe glacier recession, an assessment of current glacier thickness is important to better determine future recession. A recent effort was made to reconstruct the distributed ice thickness for all glaciers outside Antarctica and Greenland using a consensus of up to five models (Farinotti et al., 2019). This estimate generated ice thicknesses for the Northern Ice Field (NIF) and Kersten Glacier (KG) using ensembles of two and three models, respectively. The consensus estimate produces a similar mean ice thickness of $21.5 \mathrm{~m}$ for the NIF, which is in fair agreement with the observations by Bohleber et al. (2017), considering that the consensus was not informed by local thickness observations (Farinotti et al., 2019). Moreover, the recently observed separation of $\mathrm{KG}$ into two fragments (e.g., Landsat 5 scene on 22 August 2011; image courtesy of the US Geological Survey) is not in agreement with the high thickness values found in the consensus estimate.

Here, we present the first well-constrained thickness maps for $\mathrm{KG}$ and the NIF using a mass-conserving reconstruction approach introduced in Fürst et al. (2017) that readily assimilated thickness measurements (Sect. 3.3). In two different experiments we test the influence of varying input of ice thickness observations for the glacier state of 2000, where we rely on surface mass balance (SMB) data from a physically based model developed by Mölg et al. (2008, 2009; Sect. 3.1) and digital elevation data with global coverage (Shuttle Radar Topography Mission, SRTM; USGS, 2014), pursuing a new calibration strategy that uses multitemporal satellite information 


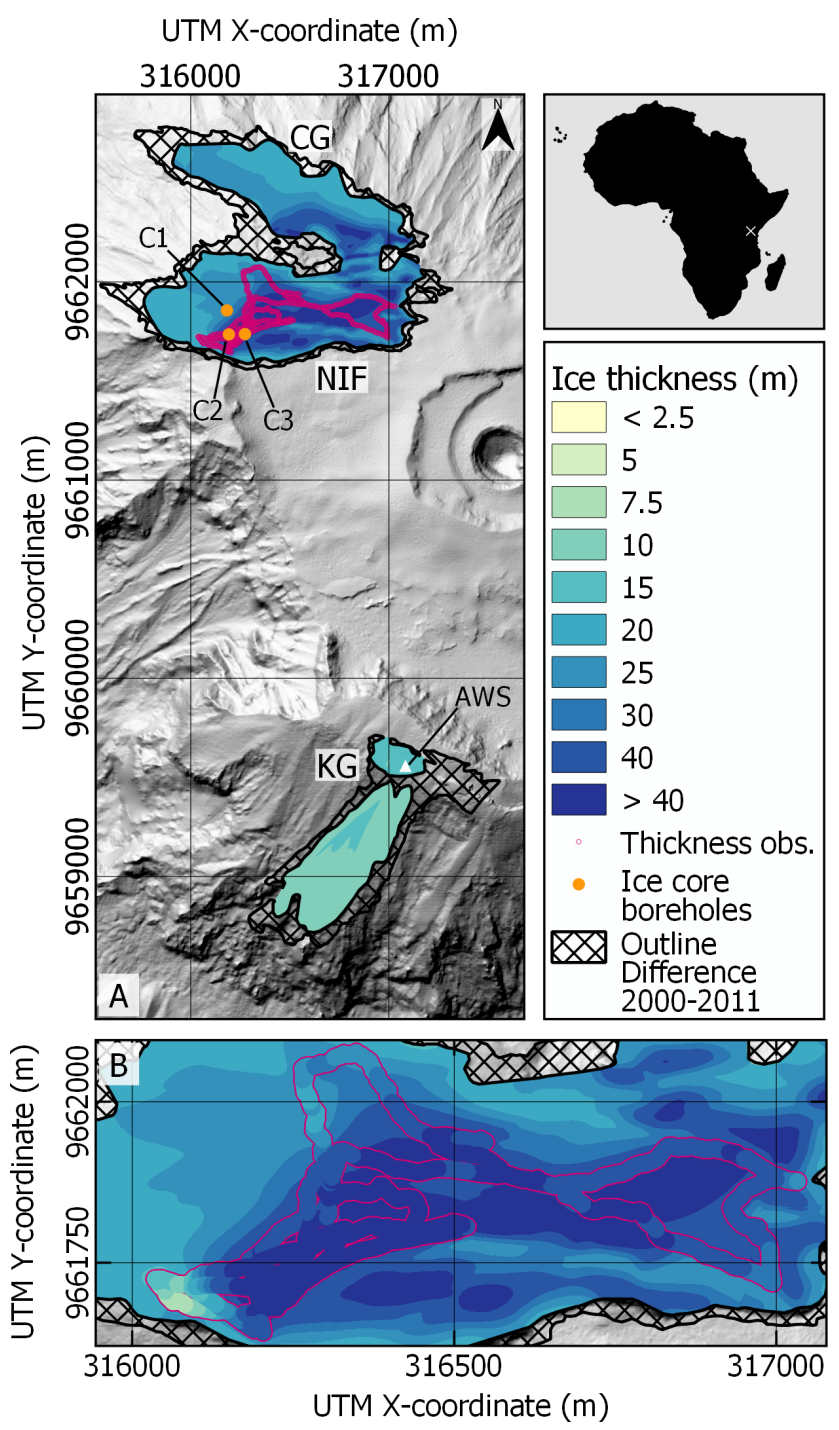

Figure 1. Reconstructed ice thickness (m) for the Northern Ice Field (NIF) and Kersten Glacier (KG) for the year 2011 based on thickness observations (NIF) and mean viscosity (KG), with a model resolution of $2 \mathrm{~m}$ (Experiment 3). The magenta path on the NIF represents the GPR ice thickness measurements by Bohleber et al. (2017). Orange dots (C1-C3) indicate the drill locations of the ice cores from Thompson et al. (2002). The AWS location from Mölg et al. (2009) is marked by the white triangle. Background: KILISoSDEM hillshade. The overview map depicts the location of Mt. Kilimanjaro (white cross) on the African continent.

on geometric changes in absence of observational ice thickness data on KG. These resulting thickness estimates are then compared to the consensus estimate (Farinotti et al., 2019). In a third experiment, we combine the very-high-resolution digital elevation model KILISoSDEM $(0.5 \mathrm{~m}$ ground resolution; Sirguey and Cullen, 2013) with the calibration strategy from the previous experiments for 2000 to produce a best estimate for the 2011 glacier state.

\section{Data}

To apply the distributed surface mass balance (SMB) model (Sect. 3.1; Mölg et al., 2008, 2009) and the thickness reconstruction (Sect. 3.3), the following input data were used: climate data measured by the automatic weather station (AWS) located on KG (Sect. 3c in Mölg et al., 2009), digital elevation information from the SRTM digital elevation model (DEM) from 2000 and the KILISoSDEM from 2012 (Sirguey and Cullen, 2013), the RGI (Randolph Glacier Inventory) 6.0 glacier outlines from 21 February 2000 (RGI Consortium, 2017), and digitized outlines based on a Landsat 5 image from 22 August 2011. The change in surface height between 2000 and 2011 was found by differencing a merger of two TanDEM-X radar images from 2011 (28 January 2011, 4 April 2011; Fig. S2; for details on the processing refer to Braun et al., 2019) and the SRTM DEM.

The central plateau area of the NIF drains westward into two glaciers, Drygalski Glacier in the south and Credner Glacier (CG) in the north. In anticipation of a future separation of the NIF, we redefine Credner Glacier to comprise the northern part of the NIF (Fig. 1). Ice thickness measurements on Kilimanjaro are limited to the NIF, where three ice cores were drilled to bedrock in 2000, with lengths from 49.0 (C1) to 50.9 (C2) and $50.8 \mathrm{~m}$ (C3; Thompson et al., 2002; Fig. 1 for borehole locations). In addition, ground-penetrating radar (GPR) profiles from September 2015 (Fig. 1) were collected by Bohleber et al. (2017). Using a kriging interpolation and the KILISoSDEM, the authors estimated the mean thickness to be between $21.2 \pm 1 \mathrm{~m}$ and $27 \pm 2 \mathrm{~m}$. For the anticipated reconstruction in 2000 and 2011, the GPR thickness measurements for the NIF are adjusted by linearly extrapolating the abovementioned elevation change information to the elapsed time between the DEM date and acquisition date of the thickness measurements.

\section{Methods}

\subsection{Mass balance modeling}

The mean annual climatic surface mass balance fields were generated using version 2.4 of the distributed, physically based mass balance (MB) model by Mölg et al. (2008, 2009), driven by meteorological input from the aforementioned AWS (Fig. S1 in the Supplement). The full MB model has already been calibrated and validated for KG. For the application on the NIF, surface meltwater is not expected to run off but rather refreeze over the very flat plateau areas (Mölg and Hardy, 2004). To properly reproduce these conditions on the NIF, we revised the model code so that refreezing of meltwater can occur on a bare ice surface with a slope angle below $5^{\circ}$ (not captured before). With these changes, the model is capable of reproducing the surface height changes observed by a sonic ranger mounted to the AWS. 


\subsection{Margin thickness generation}

For KG, no in situ thickness measurements are available. Therefore, multitemporal DEM and glacier outline information is used to infer past ice thickness. First, glacier retreat is delineated from outline information in 2000 and 2011 (Fig. 1, hatched area). In the currently ice-free area, contemporaneous elevation changes (2000-2011) then give information on past ice thickness. Positive values, which indicate a height gain in the TanDEM-X layer, were removed as a height gain outside the 2011 glacier extent implies an increase in glacier thickness from 2000 to 2011, which is unlikely. In total we removed 92 of 602 grid cells with a mean height gain of $0.19 \mathrm{~m} \mathrm{a}^{-1}$ for the NIF and 14 of 254 grid cells with a mean height gain of $0.25 \mathrm{~m} \mathrm{a}^{-1}$ for $\mathrm{KG}$.

\subsection{Ice thickness reconstruction}

Here, we apply an inverse method to infer the glacier ice thickness by assimilating surface observations and ground truth thickness measurements. A detailed description of this two-step data assimilation, of which we only used the first model step as surface velocities were not available, can be found in Fürst et al. (2017). The reconstruction approach is based on the principle of mass conservation and computes a glacier-wide flux field from the difference between the surface mass balance (Sect. 3.1) and contemporaneous elevation changes. The flux solution is converted into thickness values using the shallow-ice approximation (SIA; Hutter, 1983). This conversion involves the ice viscosity parameter $B$, which is a priori unknown. This parameter stems from assuming a Glen-type flow law, linking deviatoric stresses to strain rate components $\dot{\varepsilon}_{i j}$ via the effective viscosity $\eta=$ $0.5 B^{-1 / n} \dot{\varepsilon}^{(1-n) / n}$. Here, $\dot{\varepsilon}$ is the second invariant of the strain rate tensor (for further information on the equation see Pattyn, 2003), and $n$ equals 3 . After the flux solution is obtained, $B$ is calibrated at locations where thickness measurements are available. This point information is then expanded to the entire glacier domain using a natural neighbor Sibsonian interpolation, resulting in a spatially variable field. Before interpolating the $B$ values from each measurement location to the entire glacier basin, an average value is prescribed along the glacier outline to avoid spurious extrapolation effects.

To account for different availability of thickness measurements, Fürst et al. (2017) conducted experiments withholding 1\%-99\% of the available point measurements on several test geometries on Svalbard. Aggregate errors typically exceed $10 \%-20 \%$ of the mean glacier ice thickness when most measurements are withheld, but error values quickly reduce as measurements become available. Between the two end-member experiments ( $1 \%$ and $99 \%$ ), volumes of the test geometries differ by at most $10 \%$. Considering input uncertainties from the DEM and the SMB fields, sensitivity tests revealed that ice volume differences remain below $5 \%$ (only shown for the ice cap geometry). For more details on associated uncertainties and input sensitivities, we refer the interested reader to Fürst et al. (2017).

For the reconstruction in 2000, a nominal mesh resolution of $25 \mathrm{~m}$ was chosen. With the higher DEM quality in 2011, the resolution was iteratively increased from 25 to $2 \mathrm{~m}$ via 10 and $5 \mathrm{~m}$. The processing was conducted separately for the NIF and KG. To smooth the surface slope during reconstruction, we use a coupling length parameter (introduced in Fürst et al., 2017), which is defined as a multiple of the local ice thickness. In this way, flux streamlines become less erratic, and their alignment increases. For KG, the parameter is set to 1, a typical value for valley glaciers (Kamb and Echelmeyer, 1986). For the NIF, it had to be reduced so that the steep elevation increase at the vertical ice cliffs is depicted in the thickness field. A compromise value of 0.3 was chosen to still guarantee sufficient smoothing of the flux streamlines.

\subsection{Experimental setup}

The general strategy is to reconstruct a thickness field for $\mathrm{KG}$ and the NIF by combining SMB, elevation changes and glacier geometry with in situ measurements of ice thickness for two points in time, namely 2000 (Experiments 1 and 2) and 2011 (Experiment 3). In Experiment 1, we reconstructed the glacier state for 2000 with the generated margin thickness data (Sect. 3.2) for both the NIF and KG. As KG is rather small, we expect a homogeneous ice viscosity. In Experiment 2, we therefore decided to simply average the point information on ice viscosity and use a constant viscosity value over the entire glacier basin. In this way, lateral thickness values are no longer reproduced, but spurious spatial-viscosity variations stemming from the generic margin data are suppressed. For the NIF in Experiment 2, we chose to use the thickness measurements from Bohleber et al. (2017) as input to check how observational data influence the glacier-wide ice thickness in comparison to only using margin thickness information. In Experiment 3, the aim is to benefit from the 2011 KILISoSDEM showing very high resolution. For the NIF, the reconstruction can still be calibrated by GPR measurements from Bohleber et al. (2017) acquired in central areas. For KG, the retreat information falls outside the icecovered domain in 2011. Therefore, we use the mean viscosity information as inferred for the reconstruction in the year 2000 (Experiment 2). The KILISoSDEM is further exploited to investigate the resolution influence. Table 1 summarizes the three different experimental setups.

\section{Results}

Results show generally larger ice thickness for the NIF than for $\mathrm{KG}$ in all three experiments. For Experiment 1 (Fig. 2a), KG shows the thickest ice, of up to $15 \mathrm{~m}$, at the flat plateau parts of KG. For the central areas on the mountain flank, 

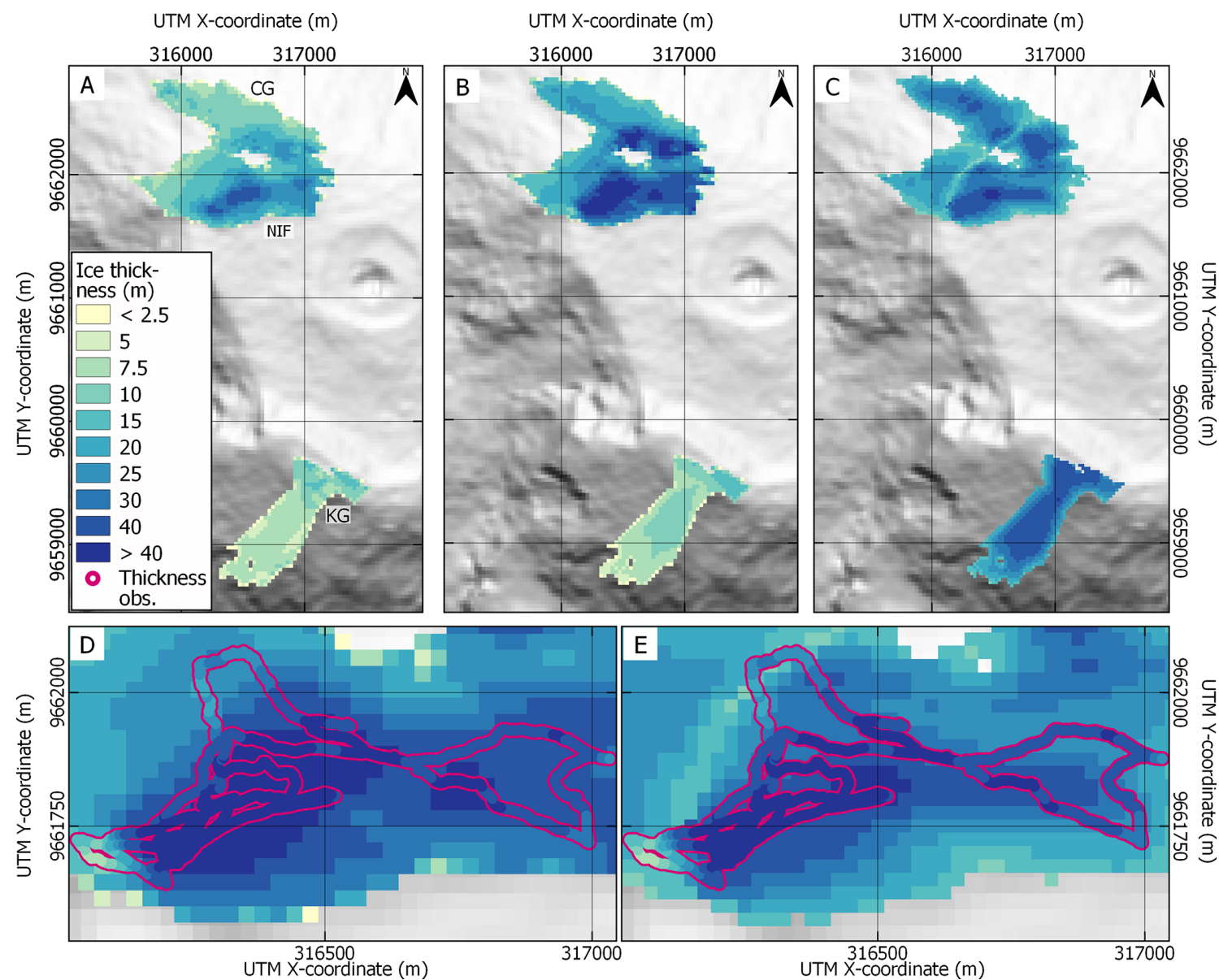

Figure 2. Reconstructed ice thickness (m) for the Northern Ice Field (NIF) and Kersten Glacier (KG) for the year 2000. Panel (a) shows results for Experiment 1, making exclusive use of past thickness information in currently ice-free areas. Panel (b) presents results from Experiment 2, which uses a bulk viscosity inferred from the retreat information on KG, whereas for the NIF, the reconstruction is only calibrated by in situ GPR measurements (see Table 1). For comparison, panel (c) depicts the composite ice thickness from Farinotti et al. (2019). Panel (d) shows a close-up of the NIF, overlying the thickness map of Experiment 2 with the GPR thickness measurements (magenta contour, showing measured values in the same color bar) by Bohleber et al. (2017). Panel (e): same as panel (d) but showing the consensus thickness map (Farinotti et al., 2019; cf. panel c). Background: SRTM DEM hillshade.

Table 1. Experimental setup of the ice thickness reconstruction (Sect. 3.4).

\begin{tabular}{|c|c|c|c|c|c|c|c|}
\hline & $\begin{array}{c}\text { Representing } \\
\text { the glacier state } \\
\text { for the year }\end{array}$ & $\begin{array}{l}\text { KG thickness } \\
\text { input }\end{array}$ & $\begin{array}{l}\text { NIF thickness } \\
\text { input }\end{array}$ & $\begin{array}{l}\text { Surface } \\
\text { elevation information } \\
\text { (year of acquisition) }\end{array}$ & $\begin{array}{l}\text { Glacier } \\
\text { outlines } \\
\text { (acquisition date) }\end{array}$ & $\begin{array}{c}\text { KG mean ice } \\
\text { thickness } \\
(\mathrm{m})\end{array}$ & $\begin{array}{l}\text { NIF mean ice } \\
\text { thickness } \\
(\mathrm{m})\end{array}$ \\
\hline Experiment 1 & 2000 & $\begin{array}{l}\text { Generated } \\
\text { margin } \\
\text { thicknesses }\end{array}$ & $\begin{array}{l}\text { Generated } \\
\text { margin } \\
\text { thicknesses }\end{array}$ & SRTM DEM (2000) & $\begin{array}{l}\text { Randolph } \\
\text { Glacier } \\
\text { Inventory } 6.0 \\
\text { (21 February 2000) }\end{array}$ & 6.2 & 13.7 \\
\hline Experiment 2 & 2000 & Mean viscosity & $\begin{array}{l}\text { Observations } \\
\text { from } \\
\text { Bohleber et al. (2017) }\end{array}$ & SRTM DEM (2000) & $\begin{array}{l}\text { Randolph } \\
\text { Glacier } \\
\text { Inventory } 6.0 \\
\text { (21 February 2000) }\end{array}$ & 6.9 & 23.4 \\
\hline Experiment 3 & 2011 & Mean viscosity & $\begin{array}{l}\text { Observations } \\
\text { from } \\
\text { Bohleber et al. (2017) }\end{array}$ & KILISoSDEM (2012) & $\begin{array}{l}\text { Digitized } \\
\text { from } \\
\text { Landsat } 5 \text { imagery } \\
\text { (22 August 2011) }\end{array}$ & 9.3 & 26.6 \\
\hline
\end{tabular}


thickness values show a mean of $6.2 \mathrm{~m}$ and locally reach up to $7.5 \mathrm{~m}$, with patches of thinner ice towards the glacier margins. The NIF is up to $40 \mathrm{~m}$ thick in its center, decreasing towards the glacier margins and towards $\mathrm{CG}$, and has a mean ice thickness of $13.7 \mathrm{~m}$. At the borehole locations C1, C2 and C3, ice thicknesses of Experiment 1 are 19.9, 23.9 and $36.6 \mathrm{~m}$ thinner, respectively (see Table S1 in the Supplement).

Results from Experiment 2 show a similar thickness pattern on KG (Fig. 2b). For the NIF, the magnitude differs significantly. Now one large part of the NIF's flat area and two smaller parts of CG exceed $40 \mathrm{~m}$. Moreover, the ice thickness in the steeper western areas of the NIF and CG has increased by a factor of 2 . The mean ice thickness also increases to $23.4 \mathrm{~m}$. At the borehole locations $\mathrm{C} 1, \mathrm{C} 2$ and $\mathrm{C} 3$, ice thicknesses of Experiment 2 are 4.4, 8.3 and $26.1 \mathrm{~m}$ thinner, respectively (see Table S1). Concerning the GPR surveys from Bohleber et al. (2017), the thickness map of the NIF (Fig. 2d) largely reproduces these measurements. Turning to the consensus estimate map (Farinotti et al., 2019), larger discrepancies prevail (Fig. 2e), especially towards the eastern part. $\mathrm{KG}$ shows a similar thickness, but the ice body on the mountain flank becomes thicker in the central parts. As before, the thickest ice patch remains on the plateau. The mean ice thickness, with $6.9 \mathrm{~m}$, is very similar to Experiment 1. In Experiment 3 (Fig. 1) we now move forward in time to 2011. Here, $\mathrm{KG}$ is split into two parts and shows an ice thickness of up to $10 \mathrm{~m}$ at the flat top part, with most of the slope being between 5 and $7.5 \mathrm{~m}$ thick. KG's mean ice thickness is $9.3 \mathrm{~m}$. The NIF's thickness distribution is similar to Experiment 2, with the thickest areas, of over $40 \mathrm{~m}$, at its flat part on the plateau. For the NIF, the decrease in thickness is less noticeable than the lateral retreat and decrease in glacier area. The mean ice thickness of the NIF in Experiment 3 is $26.6 \mathrm{~m}$. At the three ice core locations, the thickness mismatch remains comparable to Experiment 2 (see Table S1), with a mean relative absolute difference of $26 \%$. This value is rather large and exceeds inferred error estimates for the majority of glaciers on Svalbard (Fürst et al., 2017). Here, we want to use it as a rough guideline for the overall uncertainty of the 2011 reconstruction.

\section{Discussion}

We will first discuss the reconstructions for the year 2000 (Fig. 2): generally, our experiments produce results with a higher difference in thickness magnitude between $\mathrm{KG}$ and the NIF as compared to the consensus thickness map (Fig. 2c; results from Farinotti et al., 2019). For KG, no ice thickness measurements are available, and it is uncertain to what extent the generated thicknesses along the glacier margin (Sect. 3.2) are useful to inform the reconstruction. We find that the margin values result in a spatially varying viscosity field, which is transmitted into the ice thickness field (Experiment 1; Fig. 2a). As no strong viscosity variations are expected for the small $\mathrm{KG}$, a second run was conducted with constant viscosity (Experiment 2; Fig. 2b). Results indicate a thick central flow unit, as one might expect for a steep glacier, as well as a smoother ice thickness distribution, with higher thickness in the center of the glacier and thinning towards the margins. In the absence of ground truth data, it is unclear which thickness field is more plausible. However, as the thickness of most glaciers on earth is unsurveyed, the use of margin thickness information, generated from outline differences, enabled a local glacier-specific viscosity tuning which might be preferential to an empirical temperature relation (Huss and Farinotti, 2012). The consensus map shows a similar thickness pattern as Experiment 2. The most notable difference is found for the thickness magnitude of KG. For the consensus estimates, thickness values exceed $35 \mathrm{~m}$ both for the flat top part and the central steep slope part. The consensus mean thickness of $27.1 \mathrm{~m}$ is more than twice as large as in our reconstruction. Since there are no actual thickness observations for $\mathrm{KG}$, it is not certain that the ice was only up to $15 \mathrm{~m}$ thick in the year 2000 . However, KG split into two parts by 2011. The separation line follows a contour line just below the plateau. Mean elevation changes between 2000 and 2011 of $-0.64 \mathrm{~m} \mathrm{yr}^{-1}$ suggest that no more than $7 \mathrm{~m}$ of ice was present in 2000 . With $35 \mathrm{~m}$ of ice in this area, the consensus estimate seems too large.

The NIF's peculiar geometry poses a challenge, and it is difficult to reconstruct the ice thickness distribution using generic thickness observations around the margin (Experiment 1; Fig. 2a). The ice is much too thin in the interior (Fig. 2a), which underestimates the ice core lengths from Thompson et al. (2002) by $48 \%, 52 \%$ and $71 \%$ for the core locations $\mathrm{C} 1, \mathrm{C} 2$ and $\mathrm{C} 3$, respectively. When the interior GPR measurements are used as model input (Experiment 2; Fig. 2b), differences decrease to $10 \%, 17 \%$ and $53 \%$. Large mismatch values, especially for borehole C3, might also be explained by the very flat plateau. Therefore, ice motion is expected to be rather slow. Stagnant and flat areas are challenging for a reconstruction based on ice flow, and Fürst et al. (2017) show that uncertainties in the reconstructed thickness values significantly increase towards the ice divide of an ice cap. They further show that measurements along divides and ridge areas are most valuable to constrain the reconstruction approach used here. Although GPR measurements are available on the NIF plateau, we expect that uncertainties increase quickly away from these measurements. This can partly explain the mismatch with C3. Turning to the consensus estimate, the mismatch is significantly larger, with relative underestimations of $34 \%, 38 \%$ and $72 \%$ for boreholes $\mathrm{C} 1, \mathrm{C} 2$ and $\mathrm{C} 3$. The complex topography posed a similar challenge for the models participating in the consensus, especially because no thickness observations were considered for Mt. Kilimanjaro. This is also reflected in the similar mean ice thicknesses, which are $27.1 \mathrm{~m}$ for the consensus estimate (Farinotti et al., 2019) and $23.4 \mathrm{~m}$ for Experiment 2. The results for KG and the NIF point towards glacier margin 
data as thickness information that is more useful in dynamically more active areas, such as KG, instead of more stagnant and flat areas, such as the flat plateau area of the NIF.

Experiment 3 repeats the reconstruction for the year 2011 at a very high resolution. The general distribution of ice thickness is barely affected by the increase in resolution. This stability under resolution increase is assuring and illustrates the effects of inherent smoothing via the coupling length parameter that scales with the thickness. For the NIF, however, resolution is key, and the cliff geometries are much better imprinted in the final thickness map. Further experiments with 10 and 5 m model resolution (not shown) showed barely any difference in thickness distribution, verifying this effect. The mean ice thicknesses for KG and the NIF have increased in comparison to Experiment 2 from 6.9 to $9.3 \mathrm{~m}$ and from 23.4 to $26.6 \mathrm{~m}$, respectively. As observed elevation changes do not support an increase, remaining explanations comprise model resolution, outline differences and DEM quality. Resolution can be excluded based on results from a $25 \mathrm{~m}$ reconstruction in 2011 (not shown). Concerning the 2011 outlines, some internal ice-free areas (on both the NIF and KG) present in the RGI could not be confirmed from the coarse Landsat imagery, resulting in thicker ice. The four holes in the RGI outlines for KG and the NIF either stay ice-free in the 2011 outline, connect to the lateral ice-free area or are located very close to the 2011 margin. Therefore, the reconstruction accounts for these indirectly. Bohleber et al. (2017) show more even smaller ice-free spots in the western part of the NIF, which could not be confirmed from the coarse Landsat imagery, thus explaining thicker ice there. The quality difference between SRTM and KILISoSDEM is certainly also a contributing factor explaining part of the larger thickness values.

Finally, we want to briefly discuss the reconstruction approach used here with respect to other strategies for inferring distributed thickness information. The Ice Thickness Models Intercomparison eXperiments (IMTIX; Farinotti et al., 2017) concluded that as long as no thickness measurements are available, no single strategy generally outperforms the others. In this case, an ensemble result from multiple models is preferable. Yet here, observations are either available or are inferred from multitemporal satellite imagery. Measurement availability was used in the global consensus estimate to infer performance scores for the participating models (Farinotti et al., 2019), and the approach by Fürst et al. (2017) was attributed the highest value. Yet, with regard to applications on individual geometries as for Kilimanjaro, comparable results, as presented here, might well be attainable with various approaches. Regarding input requirements, approaches based on the perfect plasticity assumption are the least exigent, only requiring information on the ice geometry (e.g., Frey et al., 2014).

\section{Conclusion and outlook}

This study has a multidisciplinary character as we apply modeling approaches for glacier surface mass balance, infer remotely sensed elevation changes and utilize available information in a data assimilation. The aim of the assimilation is to accurately determine the thickness and distribution of ice for the NIF and KG on Mt. Kilimanjaro.

In the reconstructions for 2000 , we assessed the utility of this margin thickness information in constraining glacier thickness by comparing our reconstructions to the recent global consensus estimate (Farinotti et al., 2019). For Kersten Glacier, we report significantly smaller thickness values as compared to the consensus estimate, which is shown to be inconsistent with the observed glacier separation between 2000 and 2011. Our reconstructions for 2011 show mean ice thicknesses of $9.3 \mathrm{~m}$ for KG and $26.6 \mathrm{~m}$ for the NIF. A comparison of modeled thickness to the ice core lengths (Thompson et al., 2002) results in a mean relative absolute error of $26 \%$. For the NIF, our reconstruction (Experiment 2) and the consensus estimate both show a very similar mean ice thickness, which is surprising as the consensus estimate was not informed by any thickness measurements.

As ice thickness observations were not available for $\mathrm{KG}$, the reconstruction approach was calibrated with past thickness values inferred from multitemporal satellite information in areas that became ice-free in the last decade. In absence of ground truth data on $\mathrm{KG}$, it remains unclear whether the retreat information is best used spatially distributed or as a bulk average. Yet we can state that increased quality and resolution of more recent DEMs are key for capturing sharp transition zones (e.g., cliffs). The lateral-glacier-retreat information seems less utile as central ice thickness is strongly underestimated. Reasons for this worse performance might be the complex topography and the dynamic inactivity of the NIF. We therefore speculate that thickness information from retreat is most useful in areas that have been dynamically more active in the past. But we also have to acknowledge that the unique glacier settings on Mt. Kilimanjaro are certainly not ideal for this first assessment of utilizing glacier retreat information to allow a glacier-specific calibration of thickness reconstruction approaches and should be tested elsewhere to verify our results.

To conclude, glacier retreat is palpable all around the planet, and it will continue in the future (e.g., Hock et al., 2019). As time progresses, the suggested strategy to infer past ice thickness values from multitemporal satellite information will produce an increasing wealth of calibration data. Moreover, the approach is readily transferable and provides a means for glacier-specific calibration of reconstruction approaches on regional or even global scales. 
Data availability. Ice thickness fields of the 2011 reconstruction (Experiment 3) will be available at PANGAEA. See the article's web page for an update with the corresponding DOI.

Supplement. The supplement related to this article is available online at: https://doi.org/10.5194/tc-14-3399-2020-supplement.

Author contributions. CS led the writing of the manuscript, in which she received support from all authors. The research aims and setup were developed in regular discussion with JJF, TM and MB.

Competing interests. The authors declare that they have no conflict of interest.

Acknowledgements. Results presented in this publication are based on numerical simulations conducted at the high-performance computing center of the Regionales Rechenzentrum Erlangen (RRZE) of the University of Erlangen-Nürnberg. We would also like to thank Nicolas Cullen and Pascal Sirguey (both at University of Otago, NZ) for constructive discussions and for providing the KILISoSDEM.

Financial support. This research has been supported by the Deutsche Forschungsgemeinschaft (grant nos. FU1032/1-1 and BR2105/14-1).

Review statement. This paper was edited by Nanna Bjørnholt Karlsson and reviewed by two anonymous referees.

\section{References}

Bohleber, P., Sold, L., Hardy, D. R., Schwikowski, M., Klenk, P., Fischer, A., Sirguey, P., Cullen, N. J., Potocki, M., Hoffmann, H., and Mayewski, P.: Ground-penetrating radar reveals ice thickness and undisturbed englacial layers at Kilimanjaro's Northern Ice Field, The Cryosphere, 11, 469-482, https://doi.org/10.5194/tc11-469-2017, 2017.

Braun, M. H., Malz, P., Sommer, C., Farías-Barahona, D., Sauter, T., Casassa, G., Soruco, A., Skvarca, P., and Seehaus, T.: Constraining glacier elevation and mass changes in South America, Nat. Clim. Change, 9, 130-136, https://doi.org/10.1038/s41558018-0375-7, 2019.

Cullen, N. J., Sirguey, P., Mölg, T., Kaser, G., Winkler, M., and Fitzsimons, S. J.: A century of ice retreat on Kilimanjaro: the mapping reloaded, The Cryosphere, 7, 419-431, https://doi.org/10.5194/tc-7-419-2013, 2013.

Farinotti, D., Brinkerhoff, D. J., Clarke, G. K. C., Fürst, J. J., Frey, H., Gantayat, P., Gillet-Chaulet, F., Girard, C., Huss, M., Leclercq, P. W., Linsbauer, A., Machguth, H., Martin, C., Maussion, F., Morlighem, M., Mosbeux, C., Pandit, A., Portmann, A., Rabatel, A., Ramsankaran, R., Reerink, T. J., Sanchez,
O., Stentoft, P. A., Singh Kumari, S., van Pelt, W. J. J., Anderson, B., Benham, T., Binder, D., Dowdeswell, J. A., Fischer, A., Helfricht, K., Kutuzov, S., Lavrentiev, I., McNabb, R., Gudmundsson, G. H., Li, H., and Andreassen, L. M.: How accurate are estimates of glacier ice thickness? Results from ITMIX, the Ice Thickness Models Intercomparison eXperiment, The Cryosphere, 11, 949-970, https://doi.org/10.5194/tc11-949-2017, 2017.

Farinotti, D., Huss, M., Fürst, J. J., Landmann, J., Machguth, H., Maussion, F., and Pandit, A.: A consensus estimate for the ice thickness distribution of all glaciers on Earth, Nat. Geosci., 12, 168-173, https://doi.org/10.1038/s41561-019-0300-3, 2019.

Frey, H., Machguth, H., Huss, M., Huggel, C., Bajracharya, S., Bolch, T., Kulkarni, A., Linsbauer, A., Salzmann, N., and Stoffel, M.: Estimating the volume of glaciers in the HimalayanKarakoram region using different methods, The Cryosphere, 8, 2313-2333, https://doi.org/10.5194/tc-8-2313-2014, 2014.

Fürst, J. J., Gillet-Chaulet, F., Benham, T. J., Dowdeswell, J. A., Grabiec, M., Navarro, F., Pettersson, R., Moholdt, G., Nuth, C., Sass, B., Aas, K., Fettweis, X., Lang, C., Seehaus, T., and Braun, M.: Application of a two-step approach for mapping ice thickness to various glacier types on Svalbard, The Cryosphere, 11, 2003-2032, https://doi.org/10.5194/tc-11-2003-2017, 2017.

Hock, R., Bliss, A., Marzeion, B., Giesen R., Hirabayashi Y., Huss M., Radić V., and Slangen A.: GlacierMIP A model intercomparison of global-scale glacier massbalance models and projections, J. Glaciol., 65, 453-467, https://doi.org/10.1017/jog.2019.22, 2019.

Huss, M. and Farinotti, D.: Distributed ice thickness and volume of all glaciers around the globe, J. Geophys. Res., 117, F04010, https://doi.org/10.1029/2012JF002523, 2012.

Hutter, K.: Theoretical glaciology; material science of ice and themechanics of glaciers and ice sheets, D. Reidel Publishing Company, Dordrecht, the Netherlands, 1983.

Kamb, B. and Echelmeyer, K. A.: Stress-Gradient Coupling in Glacier Flow: 1. Longitudinal Averaging of the Influence of Ice Thickness and Surface Slope, J. Glaciol., 32, 267-284, 1986.

Kaser, G.: Glacier-climate interactions at low latitudes, J. Glaciol., 47, 195-204, 2001.

Mölg, T. and Hardy, D. R.: Ablation and associated energy balance of a horizontal glacier surface on Kilimanjaro, J. Geophys. Res., 109, D16104, https://doi.org/10.1029/2003JD004338, 2004.

Mölg, T., Cullen, N. J., Hardy, D. R., Kaser, G., and Klok, L.: Mass balance of a slope glacier on Kilimanjaro and its sensitivity to climate, Int. J. Climatol., 28, 881-892, https://doi.org/10.1002/joc.1589, 2008.

Mölg, T., Cullen, N. J., Hardy, D. R., Winkler, M., and Kaser, G.: Quantifying Climate Change in the Tropical Midtroposphere over East Africa from Glacier Shrinkage on Kilimanjaro, J. Climate, 22, 4162-4181, https://doi.org/10.1175/2009JCLI2954.1, 2009.

Pattyn, F.: A new three-dimensional higher-order thermomechanical ice sheet model: Basic sensitivity, ice stream development, and ice flow across subglacial lakes, J. Geophys. Res., 108, 2382, https://doi.org/10.1029/2002JB002329, 2003.

RGI Consortium: Randolph Glacier Inventory - A Dataset of Global Glacier Outlines: Version 6.0, Global Land Ice Measurements from Space, https://doi.org/10.7265/N5-RGI-60, 2017. 
Sirguey, P. and Cullen, N. J.: Surveying from Outer Space. KILISoSDEM2012: a very high resolution DEM of Kilimanjaro, Survey Quarterly, 76, 5-7, 2013.

Thompson, L. G., Mosley-Thompson, E., Davis, M. E., Henderson, K. A., Brecher, H. H., Zagorodnov, V. S., Mashiotta, T. A., Lin, P.-N., Mikhalenko, V. N., Hardy, D. R., and Beer, J.: Kilimanjaro ice core records: evidence of holocene climate change in tropical Africa, Science, 298, 589-593, https://doi.org/10.1126/science.1073198, 2002.
USGS: Shuttle Radar Topography Mission Void Filled, USGS EROS Archive, https://doi.org/10.5066/F7F76B1X, 2014. 